\title{
The Properties of Poly (Acrylic Acid) Modified with $N$ - Phenylbenzothioamide as Potential Drug Carriers
}

\author{
Halina Kaczmarek* and Magdalena Metzler
}

Faculty of Chemistry, Nicolaus Copernicus University, 7, Gagarin Str., 87-100 Toruń, Poland

\begin{abstract}
Poly(acrylic acid) and $N$-phenylbenzothioamide have been synthesized under laboratory conditions. The purity of products has been checked by FTIR and NMR spectroscopy. The obtained $N$-phenylbenzothioamide has been used for modification of poly(acrylic acid) properties. The prepared blend of PAA contained small amout of dopant (1-5 wt \%). Thermal and photochemical stability of obtained specimens were investigated using UV-Vis spectroscopy and thermogravimetric analysis. Crosslinking yield was estimated by extraction of insoluble gel formed. It was found that $N$ phenylbenzothioamide stabilizes poly(acrylic acid) during UV-irradiation which is explained by efficient crosslinking reaction.
\end{abstract}

Keywords: Crosslinking, $N$-phenylbenzothioamide, photochemical stability, poly(acrylic acid), thermal stability.

\section{INTRODUCTION}

Poly(acrylic acid), PAA, is a useful material for medical and pharmaceutical applications. This polyelectrolite is characterised by high swelling degree, biocompatibility, nontoxicity, $\mathrm{pH}$-sensitivity and mucoadhesive properties. It is a versatile polymer, which can play the role of drug delivery and protection system. Unfortunately, high water solubility of PAA critically limits its use as a mucoadhesive drug carrier. This problem can be resolved by PAA modification leading to macrochain complexation or crosslinking [1-3].

Thioamides - amide analogues containing sulfur - are building blocks in numerous pharmaceuticals [4-7]. For example, thioamide-based drugs are used to control thyrotoxicosis because they inhibit the production of thyroid hormones [5]; thiobenzanilides show anticancer action [6] and spasmolytic activity [7].

Both amides and thioamides are also valuable compounds applied to organic synthesis $[8,9]$. Moreover, thioamide groups can be incorparated into peptides, which behave as native peptides and exhibit well-known structureactivity relationships [10].

$\mathrm{N}$-phenylbenzothioamide is a photosensitive compound containing the thioamide group between two phenyl rings. Thus, chemical and photochemical activity of materials obtained by addition of this thioamide to polymer matrix can be expected.

The aim of our work was to obtain poly(acrylic acid) physically modified by addition of small amount of

*Address correspondence to this author at the Faculty of Chemistry, Nicolaus Copernicus University, 7, Gagarin Str., 87-100 Torun, Poland; Tel: (48 56) 61143 12; Fax: (48 56) 65424 77;

E-mail: halina@chem.uni.torun.pl
$N$-phenylbenzothioamide and to characterize the main properties of this material. The effect of UV-irradiation and thermal stability of pure PAA and PAA doped with thioamide has been investigated. The chemical formulae of blend components are shown below:
A<smiles>CCC(C)C(C)C(=O)O</smiles>

B

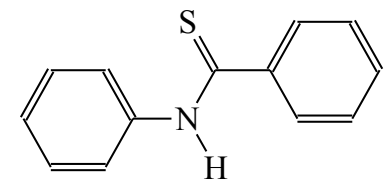

Chemical structure of poly(acrylic acid) (A) and $\mathrm{N}$ phenylbenzothioamide (B).

\section{MATERIALS AND METHODOLOGY}

\subsection{Synthesis of Poly (Acrylic Acid)}

Acrylic acid (Aldrich) has been purified by distillation under reduced pressure and then polymerized in aqueous solution in the presence of $30 \%$ hydrogen peroxide as initiator. The constant temperature during reaction was kept in the first stage: $50^{\circ} \mathrm{C}$ for 4 hours and in the second stage: $70^{\circ} \mathrm{C}$ for 6 hours. The obtained polymer was dialysed to remove the residue of monomer and water. The purity of PAA has been checked by FTIR spectroscopy using Mattson Genesis II (USA) instrument and by elemntal analysis (Vario MACRO CHN firmy ELEMENTAR Analysen systeme $\mathrm{GmbH}$ ). Found (average of 3 samples): $\mathrm{C}-49.64 \%, \mathrm{H}-$ $5.63 \%, \mathrm{O}-44.73 \%$; calculated $\mathrm{C}-50.00 \%, \mathrm{H}-5.60 \%, \mathrm{O}-$ $44.40 \%$.

The concentration of stock polymer solution has been evaluated by acid-base titration in the presence of phenolphthalein using $0.2533 \mathrm{~mol} / \mathrm{l} \mathrm{NaOH}$ solution. Thin 
solid films of PAA were obtained by solution casting onto glass plates and evaporation of solvent.

The molecular weight of PAA was measured by viscosity measurements in $2 \mathrm{M} \mathrm{NaOH}$ aqueous solution at $25^{\circ} \mathrm{C}$ by means of Ubbelohde viscometer. Average molecular weight has been calculated on the base of obtained limiting viscosity number (intrinsic viscosity, LVN) using Mark-Houwink equation. The Mark-Houwink constants $-K$ and $a$ are $42.2 \mathrm{x}$ $10^{-3} \mathrm{ml} / \mathrm{g}$ and 0.64 , respectively [11]. The viscosity average molecular weight of PAA is $395,500 \mathrm{~g} / \mathrm{mol}$.

The $\mathrm{pH}$ of PAA solutions was measured with $\mathrm{pH}$-meter (Elemetron type CP-315M) with the accuracy of $0.01 \mathrm{pH}$ unit.

\subsection{Synthesis of $N$-phenylbenzothioamide}

$N$-phenyl benzothioamide (MW $=213.3 \mathrm{~g} / \mathrm{mol}$ ) was prepared according to method described in Ref. [12]. $183.5 \mathrm{~g}$ of benzylaniline (1 mole) and $64 \mathrm{~g}$ of sulfur ( 2 moles) were heated in an oil bath at reflux until to the end of hydrogen sulfide evolution. The material was leached with $\mathrm{NaOH}$ and then neutralized by $\mathrm{CO}_{2}$. The crude product was purified by recrystallization from benzene. All used reagents were of analytical grade. Yield of reaction was $136.2 \mathrm{~g}(69 \%)$. Melting temperature $\left(\mathrm{M}_{\mathrm{p}}\right)$ was $99^{\circ} \mathrm{C}$. The structure and purity of obtained thioamide has been confirmed by NMR spectroscopy. ${ }^{1} \mathrm{H}$ NMR $(700 \mathrm{MHz})$ and ${ }^{13} \mathrm{C}$ NMR $(100 \mathrm{MHz})$ spectra in chloroform solution were recorded at room temperature with Bruker Avance III 700 and $400 \mathrm{MHz}$ spectrometers. Chemical shifts were determined relative to tetramethylsilane (TMS).

${ }^{1} \mathrm{H}-\mathrm{NMR}, \delta(\mathrm{ppm}): 8.98(\mathrm{~s}, 1 \mathrm{H}, \mathrm{NH}) ; 7.85\left(\mathrm{~m}, 2 \mathrm{H}, \mathrm{CH}_{\mathrm{Ar}}\right)$; $7.76\left(\mathrm{~m}, 2 \mathrm{H}, \mathrm{CH}_{\mathrm{Ar}}\right) ; 7.50-7.40\left(\mathrm{~m}, 4 \mathrm{H}, \mathrm{CH}_{\mathrm{Ar}}\right), 7.27(\mathrm{~m}, 2 \mathrm{H}$, $\mathrm{CH}_{\mathrm{Ar}}$ ), Fig. (1).

${ }^{13} \mathrm{C}-\mathrm{NMR}, \delta$ (ppm): 123.7; 126.7; 127.0; 128.7; 129.1; $130.0 ; 131.3 ; 139.1 ; 143.2$.

Moreover, the purity of obtained compound was also checked by thin layer chromatography (TLC) - only one analyte (i.e. one spot) has been found. Owing to high degree of purity and chemical activity, $N$-phenylbenzothioamide has been used as the substrate for synthesis of amidrazone parent substance for products applied in pharmacy and industry [9].

This compound is sometimes shortly named thioamide in this work.

\subsection{Preparation of PAA $/ N$-phenylbenzothioamide Blends}

PAA modified with $N$-phenylbenzothioamide was prepared by mixing of the $\mathrm{PAA} /$ water solution and thioamide/methanol solution to obtain the blends composed

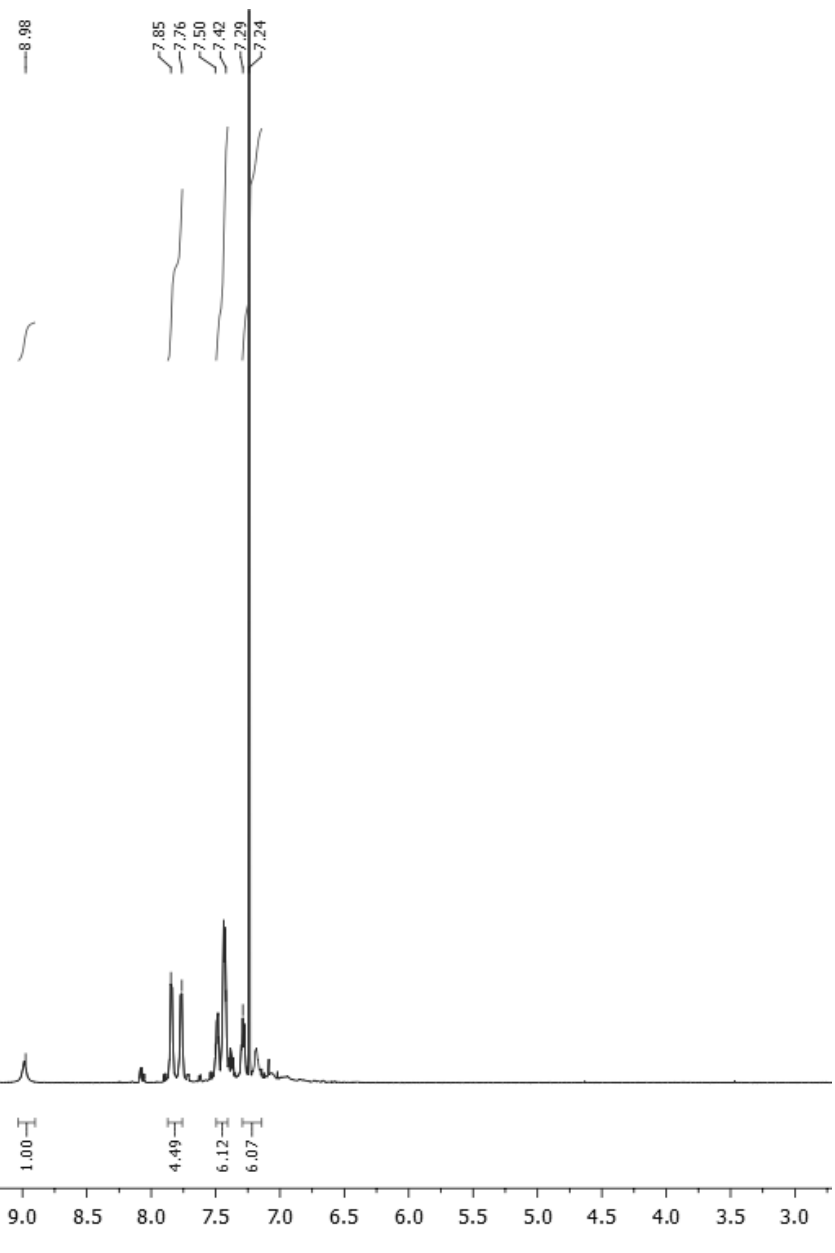

Fig. (1). ${ }^{1} \mathrm{H}$-NMR spectrum of $N$-phenylbenzothioamide. 
of $1 \%, 3 \%$ and $5 \%(w t)$ thioamide. The films were obtained by casting method at the same conditions as in the case of pure PAA. Obtained solid samples were carefully dried at laboratory conditions (room temperature, air atmosphere) and then, under vacuum to a constant weight.

\subsection{UV-Irradiation}

PAA, $N$-phenylbenzothioamide and PAA $/ N$ phenylbenzothioamide were exposed to high pressure mercury vapor lamp (HPK 125W, Philips, Holland) in solution or in solid state in air atmosphere at room temperature. The lamp emitted polychromatic radiation $(\lambda=$ $248-578 \mathrm{~nm})$. The intensity of incident light at the sample level, measured by electronic radiometer HD 9021 (Delta OHM, Italy) equipped with three probes for UVA, UVB and $\mathrm{UVC}$ ranges was $43.0 \mathrm{~W} / \mathrm{m}^{2}(315-400 \mathrm{~nm}), 35.25 \mathrm{~W} / \mathrm{m}^{2}$ $(280-315 \mathrm{~nm})$ and $8.38(200-280 \mathrm{~nm}) \mathrm{W} / \mathrm{m}^{2}$, respectively.

\subsection{UV-Vis Spectroscopy}

UV-Vis absorption spectra of diluted aqueous solutions of PAA/ $N$-phenylbenzothioamide, $N$-phenylbenzothioamide and pure PAA have been recorded using UV-1601 PC (Shimadzu, Japan) spectrophotometer in 200-800 $\mathrm{nm}$ range. Relative changes of absorbance are expressed as $\Delta \mathrm{A} / \mathrm{A}_{0}=$ $\left(\mathrm{A}_{\mathrm{t}}-\mathrm{A}_{0}\right) / \mathrm{A}_{0}$, where $\mathrm{A}_{0}$ and $\mathrm{A}_{\mathrm{t}}$ are absorbances at selected wavelength $(350 \mathrm{~nm})$ for unirradiated sample and after $t$ time of irradiation, respectively.

\subsection{Gel Amount}

The samples (before and after exposure to UV) were extracted by boiling water in Soxhlet apparatus during an $8 \mathrm{~h}$ period. The insoluble gel was dried to a constant weight. The percentage gel fraction is an average of at least three measurements.

\subsection{Thermal Stability}

The thermogravimetric analysis of studied samples was performed using a thermogravimetry analyzer (TA Instrument SDT 2920 Simultaneous DSC-TGA).
The following conditions were applied: $\mathrm{N}_{2}$ atmosphere, flow rate $-100 \mathrm{ml} / \mathrm{min}$, temperature range $-25-600{ }^{\circ} \mathrm{C}$ and heating rate $-10{ }^{\circ} \mathrm{C} / \mathrm{min}$. The samples weight was about 5$12 \mathrm{mg}$.

\section{RESULTS AND DISCUSSION}

\subsection{General Remarks and Observations}

The solutions and films of PAA and PAA doped with $N$ phenylbenzothioamide were transparent, which indicates the component miscibility. It usually assures good mechanical properties of solid state blends.

The measured $\mathrm{pH}$ of non-buffered PAA (at concentration of $\left.1.5755 \times 10^{-2} \mathrm{M}\right)$ was $3.20 \mathrm{pH}$ of $\mathrm{PAA} / N$ phenylbenzothioamide solutions was only negligibly higher (3.24-3.26) indicating slight basic character of dopant. In fact, the solution of $N$-phenylbenzothioamide ( $1 \mathrm{wt} \%$ ) has $\mathrm{pH}=9.60$.

\subsection{Gel Amount}

Table 1 presents the amount of insoluble gel formed in PAA and PAA $/ N$-phenylbenzothioamide films. It can be seen that $\mathrm{PAA} / N$-phenylbenzothioamide films become partially insoluble already after peparation (before exposure to UV). It indicates that efficient crosslinking takes place in the presence of $N$-phenylbenzothioamide. It is obvious that reaction between base (thioamide) and poly (acrylic acid) (PAA) leading to covalent bonds occurs but very high content of gel fraction suggests that also PAA selfcrosslinking is enhanced by $N$-phenylbenzothioamide. It seems probable that besides of $\mathrm{N}-\mathrm{H}$ groups participating in reaction with carboxylic groups of $\mathrm{PAA}$, also $\mathrm{C}=\mathrm{S}$ groups interact with macrochains although this bond is not strongly polarised (electronegativity of sulfur is close to carbon).

UV-irradiation causes further gel formation in all PAA doped samples. Moreover, pure PAA also undergoes efficient photocrosslinking just after $1 \mathrm{~h}$ UV. After prolonged exposure $(25 \mathrm{~h})$ the gel content in PAA is about $90 \%$ but in modified samples it exceeds even $95 \%$. The rate of photocrosslinking in all samples is highest in the first hour of UV-irradiation. Generally, the higher $\mathrm{N}$ -

Table 1. Gel fraction in PAA and PAA with different content of $N$-phenylbenzothioamide.

\begin{tabular}{|c|c|c|c|c|}
\hline \multirow{2}{*}{ Time of Irradiation (h) } & \multicolumn{5}{|c|}{ Gel Fraction (\%) } \\
\cline { 2 - 5 } & PAA & PAA + 1\% thioamide & PAA + 3\% thioamide & PAA + 5\% thioamide \\
\hline \hline 0 & 0 & 68.6 & 82.8 & 87.4 \\
\hline 1 & 58.2 & 72.6 & 87.2 & 88.6 \\
\hline 2 & 62.1 & 72.7 & 87.3 & 90.5 \\
\hline 5 & 74.0 & 76.4 & 88.7 & 91.9 \\
\hline 10 & 78.9 & 86.2 & 88.8 & 93.5 \\
\hline 15 & 86.0 & 91.1 & 90.8 & 96.5 \\
\hline 20 & 86.1 & 93.6 & 93.5 & 96.8 \\
\hline
\end{tabular}


phenylbenzothioamide content in PAA, the higher crosslinking efficiency.

\subsection{UV-Vis Spectroscopy}

Examples of UV-Vis spectra of samples irradiated in solutions are shown in Fig. (2). $\mathrm{N}$-phenylbenzothioamide in methanol solution exhibits absorption with maximum at 255 $\mathrm{nm}$. This band disappears just after several minutes of UVirradiation which is caused by photolysis of this compound (Fig. 2A). Longer exposure causes further decrease of absorbance in whole spectrum range. After approximately 2 h UV action, broad absorption appears at 260-340 nm. It

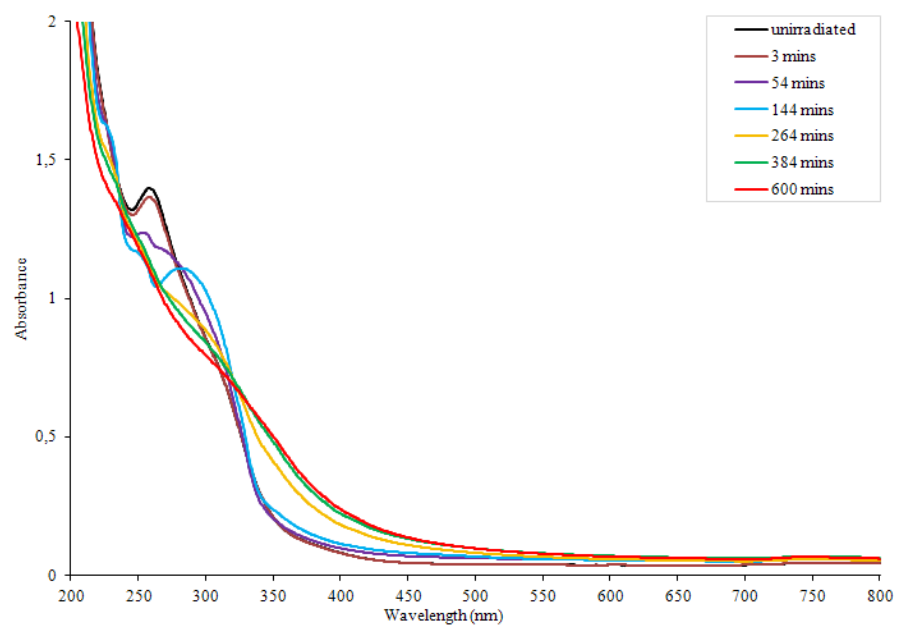

A

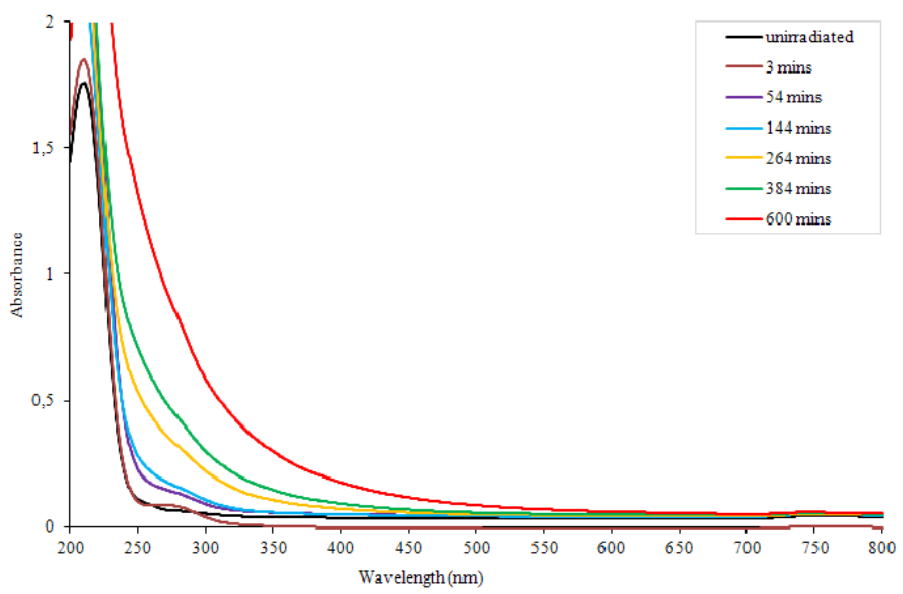

B

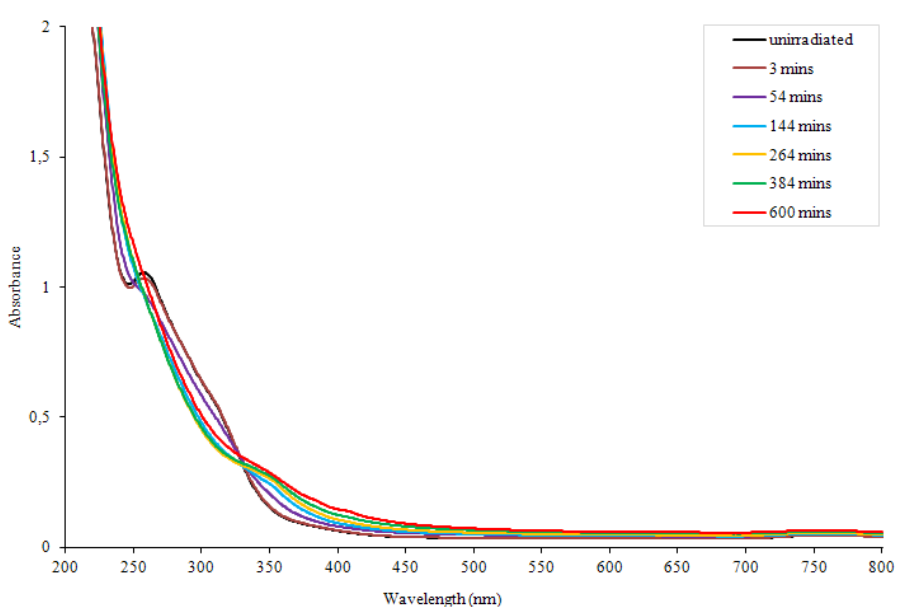

C

Fig. (2). UV-Vis spectra of $N$-phenylbenzothioamide (A), PAA (B) and PAA with 3 wt $\% N$-phenyl-benzothioamide (C) after different irradiation time. 
Table 2. Relative changes of absorbance at $350 \mathrm{~nm}$ in spectra of PAA and PAA containing 1\%, 3\% and $5 \%$ of $N$ phenylbenzothioamide after different irradiation times.

\begin{tabular}{|c|c|c|c|c|}
\hline \multirow{2}{*}{ Time of irradiation (minutes) } & \multicolumn{5}{|c|}{$\Delta \mathbf{A} / \mathbf{A}_{\mathbf{0}}(\mathbf{3 5 0} \mathbf{~ n m})$} \\
\cline { 2 - 5 } & $\mathbf{P A A}$ & PAA + 1\% thioamide & PAA + 3\% thioamide & PAA + 5\% thioamide \\
\hline \hline 6 & 0.44 & 0.05 & 0.04 & 0.17 \\
\hline 14 & 0.27 & 0.08 & 0.32 & 0.12 \\
\hline 24 & 1.02 & 0.15 & 0.59 & 0.11 \\
\hline 144 & 0.49 & 0.16 & 0.71 & 0.03 \\
\hline 324 & 2.05 & 0.07 & 0.76 & 0.03 \\
\hline 600 & 2.26 & 0.19 & 0.87 & 0.61 \\
\hline
\end{tabular}

suggests that new product of thioamide decomposition contains chromophoric groups. This intermediate product is also photo-unstable and decomposes after next hour of UV.

In the case of PAA, the main absorption lies at about 220 $\mathrm{nm}$ but there is no clear absorption maximum at longer wavelenght range (Fig. 2B). The very small branch at 250$300 \mathrm{~nm}$ due to residual impurities disappears after few minutes of exposure. UV-irradiation leads to systematic increase of absorbance at $200-800 \mathrm{~nm}$ without formation of maximum. It means that PAA photoproducts contain new types of chromophoric groups.

In unirradiated doped PAA, the band from $N$ phenylbenzothioamide at $255 \mathrm{~nm}$ is also clear (Fig. 2C). In exposed sample, the changes observed in UV-Vis spectra are caused by two overlapping effects - the disappearing of band at $255 \mathrm{~nm}$ due to the decomposition of thioamide and increase of absorbance above $340 \mathrm{~nm}$ caused by PAA photodegradation. Isosbestic point occurs at $330 \mathrm{~nm}$.

For comparison the effect of UV-irradiation in PAA and PAA with different content of $N$-phenylbenzothioamide, the relative changes of absorbance at $350 \mathrm{~nm}$ were calculated from each recorded spectrum. As can be seen, the changes caused by UV in pure PAA are always higher than those in PAA doped with thioamide (Table 2). It can be caused by PAA crosslinking which is very efficient in the presence of thioamide. The observed changes are irregular and thioamide content in PAA film (1-5 wt \%) has no particular influence on stabilizing effect.

\subsection{Thermal Analysis}

Fig. (3) and Table 3 show results of thermal analysis for $\mathrm{N}$-phenylbenzothioamide, PAA and PAA with $5 \% \mathrm{~N}$ phenylbenzothioamide before and after $25 \mathrm{~h}$ UV-irradiation.

As can be seen from Fig. (3A), $N$-phenylbenzothioamide alone decomposes in one step (almost completely) in 200$300{ }^{\circ} \mathrm{C}$ range. The small decrease of weight $(4 \%)$ at the beginning of heating is due to removal of water residue. $25 \mathrm{~h}$ UV-irradiation sligthly increases thermal stability of this compound, moreover, there is a lack of weight loss below $150{ }^{\circ} \mathrm{C}$, which indicates that water was evaporated during exposure to UV.

Thermogravimetric results for pure PAA (Fig. 3B) are in accordance with previously published data [13-15]. Three main steps of thermal decomposition are attributed to: evaporation of adsorbed water (weight loss about 4-5\%), destruction of side groups in PAA leading to decarboxylation or anhydride formation ( $25 \%$ weight loss at $200-300{ }^{\circ} \mathrm{C}$ range) and main chain scission (above $300{ }^{\circ} \mathrm{C}$ ). UVirradiation causes small increase of PAA thermal stability

Table 3. Thermal parameters of $N$-phenylbenzothioamide, PAA and PAA with $5 \% N$-phenylbenzothioamide and their changes after 25 h UV-irradiation.

\begin{tabular}{|c|c|c|c|c|c|c|c|c|}
\hline \multirow{2}{*}{ Sample/Irradiation Time } & \multirow{2}{*}{$\frac{\text { I step }}{\Delta \mathrm{m}, \%}$} & \multicolumn{3}{|c|}{ II step } & \multicolumn{3}{|c|}{ III step } & \multirow{2}{*}{$\begin{array}{l}\text { Residue at } \\
600{ }^{\circ} \mathrm{C}, \%\end{array}$} \\
\hline & & $\mathbf{T}_{\mathbf{0}},{ }^{\circ} \mathbf{C}$ & $\mathbf{T}_{\max },{ }^{\circ} \mathbf{C}$ & $\Delta \mathbf{m}, \%$ & $\mathbf{T}_{0},{ }^{\circ} \mathbf{C}$ & $\mathbf{T}_{\max },{ }^{\circ} \mathbf{C}$ & $\Delta \mathbf{m}, \%$ & \\
\hline thioamide $/ 0 \mathrm{~h}$ & 4 & 163 & 280 & 93 & - & - & - & 3 \\
\hline thioamide $/ 25 \mathrm{~h}$ & 0 & 165 & 285 & 96 & - & - & - & 4 \\
\hline $\mathrm{PAA} / 0 \mathrm{~h}$ & 5 & 172 & 277 & 25 & 300 & 425 & 55 & 15 \\
\hline $\mathrm{PAA} / 25 \mathrm{~h}$ & 4 & 175 & 260 & 24 & 303 & 430 & 58 & 14 \\
\hline $\mathrm{PAA}+$ thioamide $/ 0 \mathrm{~h}$ & 4 & 175 & 273 & 26 & 303 & 427 & 55 & 15 \\
\hline PAA+thioamide $/ 25 \mathrm{~h}$ & 3 & 177 & 268 & 28 & 316 & 430 & 54 & 15 \\
\hline
\end{tabular}




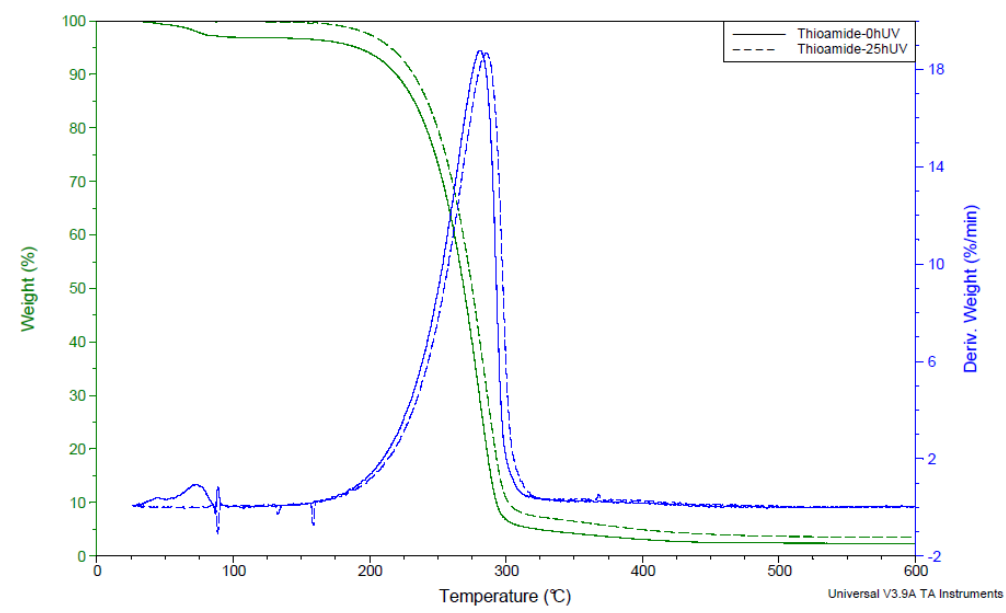

A

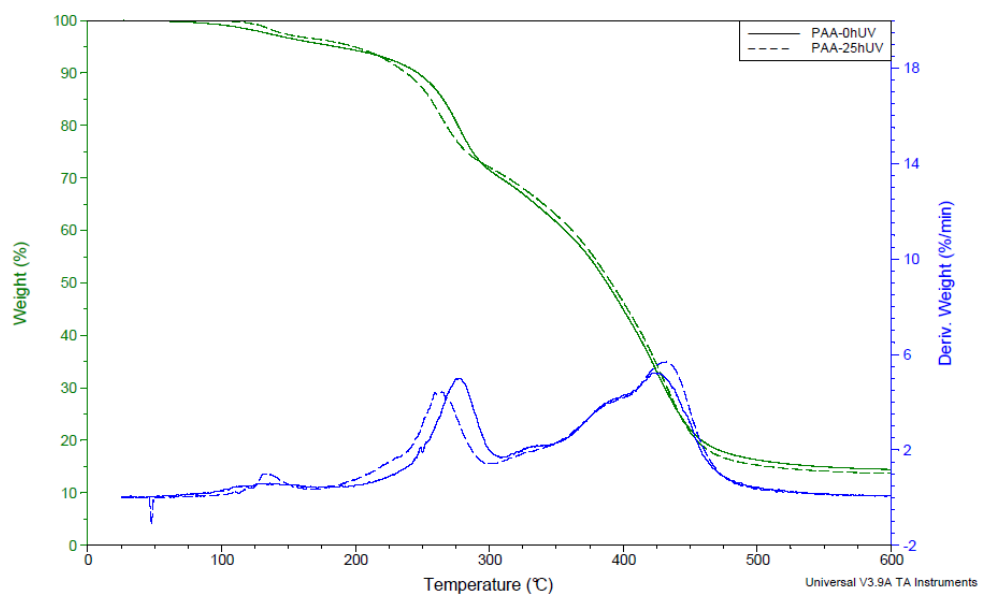

B

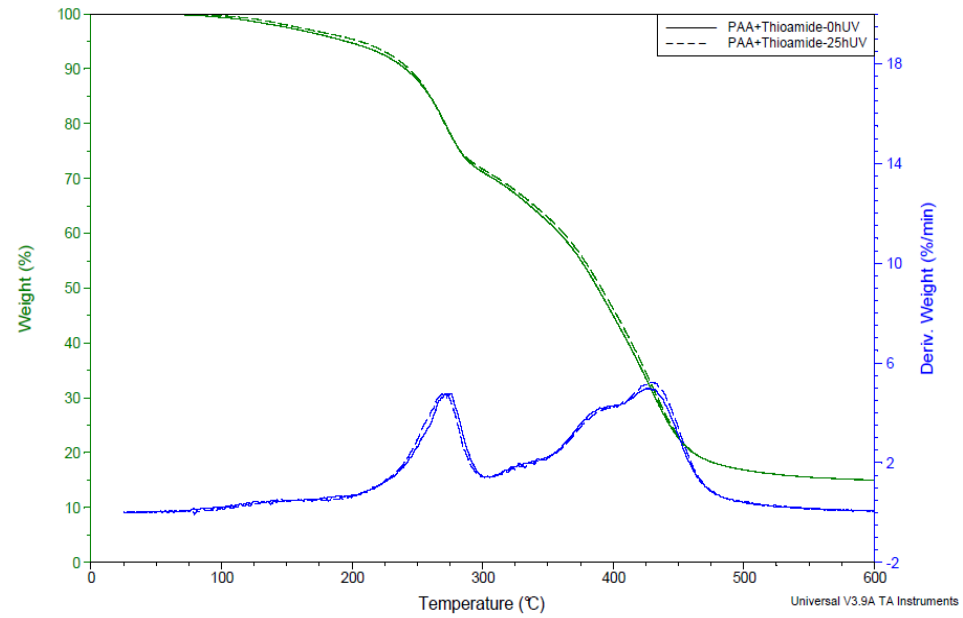

C

Fig. (3). Thermogravimetric curves (TG and DTG) of $N$-phenylbenzothioamide (A), PAA (B) and PAA with 5\% $N$-phenylbenzothioamide (C) before and after $25 \mathrm{~h} \mathrm{UV-irradiation.}$

comparing to unirradiated sample, although $\mathrm{T}_{\max }$ of the second step drops about 17 degrees.

In the presence of $N$-phenylbenzothioamide $\mathrm{T}_{0}$ of all steps slightly increases in unexposed PAA. However, $\mathrm{T}_{\max }$ of II step is negligibly shifted to lower temperature (Table 2).
The changes in thermogravimetric curve of PAA containing thioamide after $25 \mathrm{~h}$ UV irradiation are also very low (Fig. 3C). Small improvement of thermal stability in exposed blend comparing to epxosed PAA without thioamide is observed. It indicates that photochemical 
reaction between PAA and thioamide leads to more thermally stable products.

\section{CONCLUSION}

The blending of PAA and $N$-phenylbenzothioamide makes sample partially insoluble due to initiation of efficient crosslinking. Moreover, this photosensitive thioamide facilitates PAA photocrosslinking. PAA doped with $\mathrm{N}$ phenylbenzothioamide is characterised by enhanced photochemical stability comparing to PAA alone. The main reason of such stabilizing action of dopant is high content of crosslinked gel. PAA thermal degradation does not change noticeably in the presence of $N$-phenylbenzothioamide. However, in the case of UV-irradiated sample, dopant causes slight improvement of PAA thermal stability. Owing to good thermal and photochemical stability, the potential application of PAA modified with $N$-phenylbenzothioamide as drug delivery system can be expected.

\section{CONFLICT OF INTEREST}

Declared none.

\section{ACKNOWLEDGEMENTS}

The authors thank Dr. Marta Ziegler-Borowska (NCU, Toruń) for synthesis of $N$-phenylbenzothioamide.

\section{REFERENCES}

[1] Qiu, Y.; Park, K. Environment-sensitive hydrogel for drug delivery. Adv. Drug Deliv. Rev., 2012, 64, 49-60.

[2] Muller, C.; Leithner, K.; Haupstein, S; Hintzen F.; Salvenmoser, W.; Bernkop-Schnurch, A. Preparation and characterization of mucus-penetrating papain/poly(acrylic acid) nano particles for oral drug delivery applications. J. Nanopart. Res., 2013, 15, 1353.

[3] Cho, S-M.; Choi, H-K. Preparation of mucoadhesive chitosanpoly(acrylic acid) microspheres by interpolymer complexation and solvent evaporation method II. Arch. Pharm. Res., 2005, 28, 612618.

[4] Wang, F.; Langley, R.; Gulten, G.; Dover, L.G.; Besra G.S.; Jacobs Jr., R.; Sacchettini, J. C. Mechanism of thioamide action against tuberculosis and leprosy. J. Exp. Med., (JEM) 2007, 204, 73-78.

[5] Dolinkin, A. O.; Chernov'yants, M.S. Analysis of thyrostatic heteroaromatic thioamides. Pharm. Chem. J., 2010, 44, 99-106.

[6] Hu, W-P.; Yu, H-S.; Chen, Y-R.; Tsai, Y-M.; Chen, Y-K.; Liao, CC.; Chang, L-S.; Wang, J-J. Synthesis and biological evaluation of thiobenzanilides as anticancer agents. Bioorg. Med. Chem., 2008 , $16,5295-5302$.

[7] Brunhofer, G.; Studenik, C.; Ecker, G. F.; Erker, T. Synthesis, spasmolytic activity and structure-activity relationship study of a series of polypharmacological thiobenzanilides. Eur. J. Pharm. Sci., 2011, 42, 37-44.

[8] Ray, S.; Bhaumik, A.; Dutta, A.; Butcher, R. J.; Mukhopadhyay, C A new application of rhodamine as a green sulfur transferring agent for a clean functional group interconversion of amide to thioamide using reusable MCM-41 mesoporous silica. Tetrahedron Lett., 2013, 54, 2164-2170.

[9] Ziegler-Borowska, M.; Ucherek, M.; Kutkowska, J.; Mazur, L.; Modzelewska-Banacheiwcz, B.; Kędziera, D.; KaczmarekKẹdziera A. Reaction of $\mathrm{N}^{3}$-phenylbenzamidrazone with cis-1,2cyclohexane-dicarboxylix anhydride. Tetrahedron Lett., 2010, 51, 2951-2955.

[10] Yu, K-L.; Torri, A.F.; Luo, G.; Cianci, C.; Grant-Young, K.; Dantez, S.; Tiley, L.; Krystal, M.; Meanwell, A. Structure-Activity Realtionships for a Series of Thiobenzamide Influenza Fusion Inhibitors Derived from 1,3,3-Trimethyl-5-hydroxycyclohexylmethylamine. Bioorg. Med. Chem. Lett., 2002, 12, 33793382.

[11] Brandrup, J.; Immergut, E. H.; Grulke, E. A.; Abe, A.; Bloch, D. R. Polymer Handbook 4th Ed.; John Wiley \& Sons, 2005.

[12] Kokamoto, K.; Yamamoto, T.; Kanbara, T. Efficient synthesis of thiobenzanilides by willgerodt-kindler reaction with base catalysts. Synlett., 2007, 2687-2690.

[13] Dubinsky, S.; Grader, G. S.; Shter, G. E.; Silverstein, M.S. Thermal degradation of poly(acrylic acid) containing copper nitrate. Polym. Degrad. Stab., 2004, 86, 171-178.

[14] Lepine, L.; Gilbert R. Thermal degradation of polyacrylic acid in dilute aqueous solution. Polym. Degrad. Stab., 2002, 75, 337-345.

[15] Gurkaynak, A.; Tubert, F.; Yang, J.; Matyas, J.; Spencer J.L.; Gryte C.C. High-temperature degradation of polyacrylic acid in aqueous solution. J. Polym. Sci.: Part A: Polym. Chem., 1996, 34, 349-355. 